\title{
The Impact of Financial Drivers on Credit Default Swap (CDS) in Turkey: The Cointegration with Structural Breaks and FMOLS Approach
}

\author{
Mehmet Levent Erdaş1 ${ }^{\circ}$
}

\begin{abstract}
The CDS premium is considered to be an important criterion in the risk premiums of countries with emerging markets and it also provides important information about the credibility of these countries for investors. Decreasing the level of CDS for developing countries helps investors to work with the country and smoothes the way for investments in financial assets. Hence, determining the factors which can affect changes in the CDS of these countries has beco me crucial for their economies. Thus, the relationship between Turkey's CDS for 5 years and financial factors have been analyzed through the monthly data for the period between 2012 and 2020. For this purpose, the existence of the long-run relationship between the series was investigated by Gregory-Hansen (1996) and Hatemi-J (2008) and it was seen that the series are cointegrated. Afterwards, the long-run coefficients between the series were estimated by FMOLS. The results indicate that the BIST100 index and liquid liabilities have a positive effect on CDS and that the domestic credit volume of the banking sector has a negative effect on CDS. Furthermore, the estimated break dates suggest that significant events are occurring in the Turkish economy.
\end{abstract}

Keywords

Credit Risk, Financial Factors, Structural Breaks, Cointegration, Turkey

\section{Introduction}

Rational investors have a desire to predict the price fluctuations of potential investments to avoid future uncertainties and risks. Similarly, foreign investors consider not only the bond yield and return of the relevant country, but also whether or not the relevant debt can be repaid after they invest in a country. Issues such as macroeconomic stress and policy changes make it difficult to estimate the expected returns, thus making good risk management necessary. All these developments make it necessary for those market participants who desire to make investments to have adequate information related to local markets to make proper decisions. However, it is difficult and expensive for each market participant to access that information

1 Corresponding Author: Mehmet Levent Erdaş (Asst. Prof. Dr.), Akdeniz University, Serik Faculty of Business, Department of Economics and Finance, Antalya, Turkey. E-mail: leventerdas@gmail.com, ORCID: 0000-0001-6594-4262

To cite this article: Erdas, M.L. (2021). The Impact of Financial Drivers on Credit Default Swap (CDS) in Turkey: The Cointegration with Structural Breaks and FMOLS Approach. Istanbul Business Research, 51(1). Advanced Online Publication. http://doi.org/10.26650/ibr.2021.51.895637 
with their potentials (Dinc et al., 2018: 182). Additionally, fast-developing technologies and globalization have led to innovations in financial markets and have made the development of different financial instruments for several needs necessary. All of these factors have made investors apply for financial instruments to avoid risks (Baltaci and Akyol, 2016: 610). Hence, other financial instruments, which have emerged to assist in avoiding credit risk and are increasingly common, are credit derivatives.

It is increasingly common for companies and developing countries to apply for credit derivatives, which enable the trading of credit risk (in other words, aim to manage credit risks). One of the most widely sought after credit derivatives in financial markets has been the CDS (Hull et al., 2004: 2790; Hull and White, 2001: 12). The CDS, one of the most important credit derivatives within financial markets, has also become one of the main indicators that is used in evaluating the risk perception related to a country (Atmisdortoglu, 2019: 42). Policymakers and researchers have begun to carefully follow the mobility in CDS premiums. CDS protects the creditor party against the risk of non-repayment of a loan in return for a certain premium and undertakes the role of protection against the value loss or damage which may occur in the related asset. It was first introduced to the financial world by the US-based investment bank JP Morgan Chase in 1995 (Danaci et al., 2017: 68). CDS is a financial derivative product acting as a kind of insurance by providing protection against the risk of incomplete and deferred payments for debt instruments issued by a country or a company (Amato, 2005: 56; Sarigul and Sengelen, 2020: 206). Its purpose is to get rid of the risk of bankruptcy of the creditor and the debtor. The CDS vendor then bears this risk, which naturally requires a determined fee. The fees which are paid to third parties for insurance are called CDS premiums or CDS spreads (Akkaya, 2017: 130). The CDS premium is the rate that evens up the current values of the expected receipt and expected loss amounts and is mostly determined through the expectations of the market participants about the default potential of the financial assets. Thus, the creditors bear the risk of not being able to collect their receivables from the CDS vendor. In this respect, CDS ensures that the credit risk is transferred from the protection buyer to the protection seller in return for a determined payment (Fontana and Scheicher, 2010: 5).

The CDS premium provides important information on the performance of the real economy and helps early detection of possible risks and damages, especially in developing countries, with increasing risk premiums to the global financial system. The increase in the CDS premium causes an increase in macroeconomic uncertainty and may negatively affect the decision processes of direct or indirect investments proposed for a country. Due to its role in the financial markets, the number of studies conducted to determine the variables affecting CDS premium has increased in recent years, with an emphasis on analyzing the relationships between macroeconomic and financial variables. In this study, those financial variables in Turkey which may affect the CDS premium are analyzed. Within this framework, the aims of our study were to determine the dates of structural breaks on the monthly CDS premium, 
which are determined by considering the 5-year CDS base ratings of Turkey between March 2012-2020, to reveal the economic and political factors causing those breaks, and to question whether the selected financial variables affect the CDS premium. In this research, in which the effects of financial variables on the CDS premium are analyzed, it is thought that studies which analyze the structural break models and the dynamic relationship between the variables are limited by considering the national and international literature and it is discovered that the studies analysing the risk perception for Turkey are conducted through weighted credit ratings and therefore it is understood that this study will contribute to the literature.

The structure of the paper is as follows: after the Introduction, Section 2 provides a brief literature review on financial and macroeconomic determinants of CDS premiums. Sources of the data as well as methodology are presented in Section 3. Section 4 presents the empirical results of the determinants of Turkey's CDS premium. In the last section, all findings are interpreted within the frame of the literature, and policy recommendations are proposed.

\section{Review of Literature}

In parallel with the increase in the transaction volume of the CDS premium in the financial markets, the importance of the CDS premium within the economic literature also increases. With the recent financial developments, those studies on the macroeconomic and financial variables related to the CDS premium and which affect those premiums have become popular. The key determinants of CDS premiums such as high volatility in global financial markets and frequent changes in risk appetite (Pan and Singleton, 2008, Longstaff et al., 2011; Fender et al., 2012; Fontana and Scheicher, 2016 are discussed in the current literature). A summary of those studies conducted on those relationships is provided below.

Chan et al. (2008) evaluated the dynamic relationship between sovereign CDS spreads and stock prices for seven Asian countries for the period from 2001 to 2007 using the Merton type structural model. They found that there is a strong negative correlation between CDS spreads and stock indexes for most Asian countries. Ersan and Gunay (2009) focused on examining the effects of the financial developments on CDS spreads. They applied VAR models. The results indicated that the Eurobond incomes and Dow Jones Index incomes variables were factors that had an affect on the country's spreads instead of local factors. Zhang et al. (2010) examined the CDS premium associated with exchange rates by using Granger causality and found that the CDS index differences provide carry-trade information. Longstaff et al. (2011) analyzed the sovereign credit risks through the CDS data obtained from developed and developing countries for the period between 2000 and 2010, and they found that the sovereign credit risk can be related to global factors instead of national factors. The results indicated that the CDS premium of the countries has a closer relationship with the volatility risk premiums expressed with the USA share market and higher-yielding markets as well as the VIX 
index. Liu and Morley (2012) studied the connection between the CDS spread, exchange rate, and the financial stability for the United States and France by applying the Autoregressive (VAR) and Granger causality. The study reported that the exchange rate has significant effects on the CDS while the interest rate has a limited effect on the CDS. Coronado et al. (2012) aimed to explore the association between stock indexes and the sovereign CDS market. The results suggested that sovereign CDS has a negative correlation with stock indexes. Ertugrul and Ozturk (2013) have investigated the relationship between CDS spreads and financial market indicators for the selected emerging market countries. The results suggest that the CDS spreads have a cointegration relationship with the remaining financial market indicators. The results also reveal that the CDS spread is negatively related to market uncertainties. Aizenman et al. (2013) analyzed the factors affecting the CDS premium for Greece, Ireland, Italy, Portugal, and Spain in particular to estimate the credit risk pricing of sixty countries within the period between 2005 and 2010. The results of the analysis indicated that the TED margin, trade openness index, foreign debts, and inflation have important roles in the CDS premium. Eyssell et al. (2013) analyzed Chinese data to research the determinants of the CDS premium. In the research in which the VAR analysis method was used, data obtained from the stock index, real interest rate, and S\&P 500 were used. It was discovered that the changes in the Chinese spreads affect the changes in the stocks. Hanci (2014) examined the existence of the relation between CDS spreads and the BIST100 index in Turkey between 2008 and 2012 by applying the GARCH method. The results revealed that the BIST100 index was associated negatively with CDS spreads. Koy (2014) analyzed the relationship between the CDSs and Euro bonds premiums of the eight countries through the daily data obtained from the period between 2009 and 2012 by applying Johansen cointegration and Granger causality tests. A causality relationship between the CDSs and Euro bond was detected. Yenice and Hazar (2015) used correlation analysis to examine the relationship between the stock exchange, exchange rate, and CDS premium, focusing on developing countries (including Turkey) from 2009 to 2014. The results showed that the CDS premium correlates with the stock exchanges and exchange rates of countries. Bozkurt (2015) examined the relationship between the CDS premium and financial stability using fuzzy regression analysis. The results indicated that there is a long-term relation between the NPLs and the macroeconomic variables, and the results of the Granger causality test indicated that the mentioned relations are dual. It was concluded because of the study that there is a negative relationship between financial stability and CDS premium. Gun et al (2016) focused on determining whether the 2013 Gezi Park events caused a significant impact on Turkish CDS spreads or not for the period between 2010 and 2015 by using the VAR method, Johansen cointegration test, and causality with the Granger test. They found a significant relationship between CDS spread Euro bond interest, BIST-100 index, foreign currency basket, and bond yield. The results also suggest that there were significant correlations between the Gezi Park events and CDS spread. Eren and Basar (2016) discovered that CDS premium affects the stock market prices positively in a long-term 
period in the study where they analyzed the effects of the CDSs and macroeconomic factors on the BIST-100 index. The monthly data related to the variables of the ARDL model, inflation interest rate, foreign exchange rate, money supply, foreign trade balance, and CDS price for the period between 2005 and 2014. Baltaci and Akyol (2016) used the dynamic panel data method to examine the determinants of the CDS in developing countries (including Turkey) throughout quarterly data of 2004-2008. The results of the GMM analysis indicated that the CDS spreads are affected by many macroeconomic factors. Degirmenci and Pabuccu (2016) tried to explain the relationship between the Istanbul Stock Exchange and CDS premiums and they discovered a bilateral relationship between BIST-100 and CDSs for the period between 2010 and 2015. They applied VAR analysis, Granger causality analysis, and the Artificial Neural Network-based NARX method in their study. Kocsis and Monostori (2016) researched the relationship between the fundamental macro-financial indicators and the CDS premium of 13 Eastern European countries for the period between 2008 and 2014. In their study, in which they categorized macro-financial indicators as real growth, external position, financial status, banking sector vulnerability, and political-institutional development, they discovered that national factors are far more effective in explaining the CDS premium rather than the global factors. Aksoylu and Gormus (2018) studied the relation between the financial drivers and CDS premium in nine countries from 2005 to 2015. The results indicated that there is an asymmetric causality relationship between the CDS premium and the financial drivers. Munyas (2018) evaluated the connection between the CDS premium and the market data for Turkey by employing regression analysis. Their results suggest that the BIST-100 index is related negatively with CDS premiums while the Dollar exchange rate and bond interest rate are not statistically significant. Mateev and Marinova (2019) studied the relation between the CDS and market price of Markit iTraxx Europe index companies between 2012 and 2016 using linear and non-linear models that allowed for structural breaks. The results indicated that CDS spreads and stock prices are cointegrated and there are long-run relations between the CDS spreads and stock prices. Kilci (2019) analyzed the relationship between the foreign debt/GDP rate and countries' CDS premium for the period between 2000Q1 and 2018Q2. In the analysis, the Fourier cointegration test and Granger causality test were applied through the data obtained from the quarter periods. The results indicated that there is a positive relationship between the variables. Atmisdortoglu (2019) conducted research to determine the stock exchange, interest rate, and exchange rate of CDS premiums using data of the emerging markets over the period 2010-2019 and employed VAR analysis. The results revealed that the stock exchange had the largest effect among the selected variables, whereas the exchange rate and interest rate had no significant effect. Avci (2020) studied the association of the CDS spreads with equity markets in Turkey between 2003 and 2018 using cointegration with structural breaks and causality methods. The results suggested that there is cointegration among the variables and unidirectional causality from BIST-100 to CDS premium. Sevil and Unkaracalar (2020) examined the link between CDS spreads for Turkey and portfolio investments 
for the period of the quarterly data from 2010 to 2018 using the FMOLS test. The findings suggest that there is a negative relationship between portfolio investments and CDS spreads.

\section{Data and Methodology}

In this study, the relationship between Turkey's 5-year CDS premium and the BIST100 index, the domestic credit volume for the banking sector, exchange rate, and liquid liabilities are analyzed. The data collected comprises monthly data between March 2012 and March 2020 and consists of 97 observations. The reason for applying the five-year CDS premium is because it are more liquid compared to the ten-year CDS premium (Hull and White, 2001; Longstaff et al., 2011; Hull, 2012). The data was obtained from the Central Bank of the Republic of Turkey and investing.com. Since the results of the logarithmic form are better than the linear form, all data are further expressed in their natural log forms.

Reasons such as economic crises, changes in the economic policies, political instability financial instability, and natural disasters can cause structural breaks on the economic time series (Bozkurt and Okumus, 2015: 27). Hence, structural breaks on the time series are investigated in the cointegration analyses in which the balanced relationship between the economic variables is common (Altay and Yilmaz, 2016: 80). Several social and political issues such as economic crises in Turkey have been effective on the macroeconomic variables. Those effects created a change on the average or variance of the time series variables or sometimes on both their average and variance (Caglar and Mert, 2017: 25). Therefore, the cointegration tests with structural breaks in the study consider those effects. In the study, the relationship between the variables through applying cointegration and causality tests test the financial relationship.

The empirical analysis of the study consists of three main parts. Firstly, the Phillips-Perron (PP) (1988) unit root test and the Lee and Strazicich (2003) with two structural breaks unit root test are applied to test the unit-roots and stationarity of the variables. Without taking the existence of the structural breaks in the cointegration equation, the cointegration tests can provide deviant results. Therefore, since the existence of structural breaks can affect cointegration relationships, the cointegration tests developed by Gregory-Hansen (GH) (1996) and Hatemi-J (2008) which take the structural breaks into consideration are applied at the second stage of the analysis. When the findings are evaluated, considering the structural breaks for modelling the long-term relationship of cointegration relationship will make the results more significant. In case the relevant variables are cointegrated, the long-term estimate coefficient will be obtained through the fully modified least square (FMOLS) methods which were suggested by Stock and Watson (1993).

GH (1996) is a test in which the structural breaks are determined internally, and which allows a single structural break (Gregory and Hansen, 1996: 555). Another important point of 
this test is the ability to treat the issue of a break (which can be determined endogenously) and cointegration together (Le and Chang, 2012: 89). In the GH (1996) test which is the extension of the Zivot-Andrews (1992), single-equational regression models were developed to analyze the cointegration relationship considering the structural breaks (Yilanci and Ozcan, 2010: 26). To account for one endogenous break, Gregory and Hansen (1996a, 1996b) propose the following three models which are level shift, level shift with the trend, and intercept with slope shifts (Gregory and Hansen, 1996: 102-103):

Model C (level shift)

$$
y_{t}=a_{1}+a_{2} \vartheta_{1 \tau}+\delta_{1} y_{2 \tau}+e_{t}, \quad t=1, \ldots, n
$$

Model C/T (level shift with trend):

$$
y_{t}=a_{1}+a_{2} \vartheta_{1 \tau}+b t+\delta_{1} y_{2 \tau}+e_{t}, \quad t=1, \ldots, n
$$

Model C/S (regime shift):

$$
y_{t}=a_{1}+a_{2} \vartheta_{1 t}+\delta_{1} y_{2 \tau}+\delta_{2} y_{2 \tau} \vartheta_{1 \tau}+e_{t}, \quad t=1, \ldots, n
$$

where $\alpha_{1}$ is the intercept before the break and $\alpha_{2}$ is the change in intercept at the time of the break, $y_{2 \tau}$ is an m-dimensional vector of explanatory variables and et is the disturbance term. In the $3^{\text {rd }}$ Model,$\delta_{1}$ is the cointegrating slope coefficient before the shift and $\delta_{2}$ is the change in the cointegrating slope coefficient at the time of the break (Gregory and Hansen, 1996: 102-103). In equations (1), (2) and (3), $\vartheta_{1 \tau}$ is a dummy variable. To model the structural change, GH (1996) defined the indicator variable as follows:

$$
\vartheta_{1 \tau}=\{0, t \leq[n \tau] 1, t>[n \tau]\} \quad 0.15<\tau<0.85
$$

Here, $\vartheta_{1 \tau}$ is a dummy variable, $n$ is the number of observations, $\tau$ is the unknown parameter $(0,1)$ denotes the relative timing of the break point and [ ] denotes integer part.

For each of the above three models, unit root tests are applied on the residuals series employing $A D F^{*}, Z_{t}^{*}$ ve $Z_{\alpha}^{*}$ tests. Here, to test the cointegration relationship GH (1996) propose the following tests (Mert and Caglar, 2019: 378):

$$
\begin{aligned}
& A D F^{*}=A D F(\tau) \\
& Z_{t}^{*}=Z_{t}(\tau) \\
& Z_{\alpha}^{*}=Z_{\alpha}(\tau)
\end{aligned}
$$


The $Z_{\alpha}$ statistic can be defined as follows:

$$
Z_{\alpha}(t)=n\left(\hat{\rho}_{t}^{*}-1\right)
$$

Finally, the $Z_{t}$ statistic can be defined as follows

$$
Z_{t}(\tau)=\frac{\left(\hat{\rho}_{\tau}^{*}-1\right)}{\hat{s}_{\tau}}
$$

For the GH (1996) cointegration test with a break, the single possible regime change (single break) is taken into consideration; however, multiple breaks on the cointegration coefficient during the period under analysis can cause changes in the long-term relationship between the series. In cases of multiple breaks in those variables, the test results with a single break will be weaker. To solve this problem, Hatemi-J (2008) contributed to the literature by developing the GH (1996) method through the existence of two breaks and by considering two possible regime changes (double break). Therefore, the Hatemi-J (2008) cointegration test is an extended version of the GH (1996) cointegration test by allowing two structural breaks. With the Hatemi-J (2008) test, the breaks can be modeled through only the regime change $(\mathrm{C} / \mathrm{S})$ model and the break point is determined internally in the test strategy.

The first of them is the GH (1996) cointegration model, which contains an endogenous break. Hatemi-J (2008) considers only a model with regime shift in which two endogenous breaks affect both the intercept and the slopes coefficients. Here, he revealed that cointegration analysis can be performed even in the presence of two breaks in the series

The model which is identified as $\mathrm{C} / \mathrm{S}$ is presented by:

$$
y_{t}=a_{0}+a_{1} D_{1 t}+a_{2} D_{2 t}+\beta_{0}^{\prime} x_{t}+\beta_{1}^{\prime} D_{1 t} x_{t}+b_{2}^{\prime} D_{2 t} x_{t}+u_{t}
$$

where, $\alpha_{0}$ indicates the first structural break, $\alpha_{1}$ indicates the break caused by the first structural break, and $\alpha_{2}$ indicates the break caused by the second structural break. While $\beta_{0}$ indicates the slope parameter before the structural changes, $\beta_{1}$ indicates the effect of the first structural change on the slope, and $\beta_{2}$ the effect of the second structural change is the parameter. In equation (8), $D_{1 t}$ and $D_{2 t}$ are dummy variables which include the effects of structural breaks in the model and are defined as follows (Mert and Caglar, 2019: 379):

$$
D_{1 t}=\left\{0, t \leq\left[n \tau_{1}\right] 1, t>\left[n \tau_{1}\right]\right\} \text { ve } D_{2 t}=\left\{0, t \leq\left[n \tau_{2}\right] 1, t>\left[n \tau_{2}\right]\right\}
$$

In equation (9), the unknown parameter $\tau_{1}$ and $\tau_{2}$ indicate the breakpoints. Three different statistics are proposed to test the null hypothesis. The null hypothesis shows that there is no cointegration. These are the test statistics for $A D F^{*}, Z_{t}^{*}$ and $Z_{\alpha}^{*}$. Here, the ADF test statistic is calculated based on the $t$ test value, which is the slope $u_{t-1}$. In order that $Z_{a}, Z_{t}$ values can be calculated $\hat{p}^{*}$. The $\hat{p}^{*}$ term is calculated by the formula below (Hatemi-J, 2008: 499): 


$$
\hat{p}^{*}=\frac{\sum_{t=1}^{n-1}\left(\widehat{u}_{t \tau} \widehat{u}_{t+1}-\sum_{j=1}^{B} w(j / B) \widehat{\gamma}(j)\right)}{\sum_{t=1}^{n-1} \widehat{u}_{t}^{2}}
$$

After the coefficient $\hat{p}^{*}$ is estimated,

$$
\begin{aligned}
& Z_{\alpha}=n\left(\hat{\rho}^{*}-1\right) \\
& Z_{t}=\frac{\left(\rho_{\tau}^{*-1}\right)}{\left(\widehat{\gamma}(0)+\frac{2 \sum_{j=1}^{B} w(j / B) \widehat{\gamma}(j)}{\sum_{t=1}^{n-1} \widehat{u}_{t}^{2}}\right)}
\end{aligned}
$$

Here, the term $\hat{\gamma}(0)+2 \sum_{j=1}^{B} \quad w\left(\frac{j}{B}\right) \hat{\gamma}(j)$ is the long-term variance of the residues obtained from the regression of $\hat{u}_{t}$ on $\hat{u}_{t-1}$ indicates the forecast.

As the test method is based on the minimum achievement of the three test statistic depending on the $\tau_{1}$ and $\tau_{2}$ values, Hatemi-J (2008) suggests the following tests:

$$
\begin{aligned}
& A D F^{*}=A D F\left(\tau_{1}, \tau_{2}\right) \\
& Z_{t}^{*}=Z_{t}\left(\tau_{1}, \tau_{2}\right) \\
& Z_{\alpha}^{*}=Z_{\alpha}\left(\tau_{1}, \tau_{2}\right)
\end{aligned}
$$

In order to calculate the long-term estimate coefficient, the FMOLS estimator method is employed. The FMOLS method was developed by Phillips and Hansen (1990) to administer an optimal cointegrating regression estimation that has a combination of $I(1)$. This test explicates problems such as endogeneity, serial correlation, measurement errors and allows for the heterogeneity in the long-run parameter (Phillips and Hansen, 1990: 120; Bashier and Siam, 2014; Adom et al., 2015). Therefore, the FMOLS method is preferred to estimate the longterm and short-term coefficients in which the structural breaks can be included in the model as dummy variables.

When the mathematical form $(n+1)$ of this model is expressed with the dimensional time series vector, it is presented with the following equation (Phillips and Hansen, 1990):

$$
y_{t}=X_{t}^{\prime} \beta+D_{1 t}^{\prime} \gamma_{1}+u_{1 t}
$$

Here $y_{t}$ is the dependent variable $I(1) . D_{t}=\left(D_{1 t}, D_{2 t}{ }^{\prime}\right)$ indicates deterministic trend variables, $u_{1 t}$ indicates zero mean and error term with covariance $(\Omega)$. The $n$ stochastic variables are determined by the $X_{t}$ equation.

$$
\begin{aligned}
& X_{t}=\Gamma_{21}^{\prime} D_{1 t}+\Gamma_{22}^{\prime} D_{2 t}+\varepsilon_{2 t} \\
& \Delta_{\varepsilon 2 t}=u_{2 t}
\end{aligned}
$$

The FMOLS estimator is given by:

$$
\theta_{F M O L S}=\left[\begin{array}{ll}
\hat{\beta} & \hat{y}_{1}
\end{array}\right]=\left[\begin{array}{ll}
\sum_{t=1}^{T} & Z_{t} Z_{t}^{\prime}
\end{array}\right]^{-1}\left[\begin{array}{ll}
\sum_{t=1}^{T} & Z_{t} y_{t}^{+}-T\left[\hat{\lambda}_{12} 0\right.
\end{array}\right]
$$


Here $Z_{t}=\left(X_{t}^{\prime} D_{t}^{\prime}\right)^{\prime}$ and $y_{t}^{+}=y_{t}-\widehat{\omega}_{12} \widehat{\Omega}_{22}^{-1} \widehat{u}_{2}$ represent the converted data. Estimation with long-term variance-covariance matrices and related elements are estimated using the equation $\hat{\lambda}_{12}^{+}=\widehat{\omega}_{12} \widehat{\Omega}_{22}^{-1} \hat{u}_{12}$ and $u_{t}=\left(\hat{u}_{1 t}^{-1}, \hat{u}_{2 t}^{-1}\right)^{\prime}$ is the deviation correction term (Adom et al., 2015; Mehmood and Shahid, 2014: 60).

\section{Empirical Results}

In the study, the unit root test and cointegration test methods are applied to test the relationship between the variables within the frame of the risk premium. The empirical analysis consists of three sections. First, the stationarity of the series is analyzed through a unit root test. Then, the cointegration test method is used to test the long-term relationships. Finally, the elasticity of the variables is calculated through the long-term coefficient estimator. Before the analysis, the characteristics of the variables included in the model are mentioned. Descriptive statistics are used to control the behavior of financial variables. Table 1 shows the descriptive statistics for the data set employed in this study.

Table 1

Descriptive Analysis of the Variables

\begin{tabular}{lcccccc}
\hline Variables & Mean & Median & Maximum & Minimum & Std. Dev. & Jar-Bera \\
\hline CDS Premium & 246.6651 & 233.8300 & 546.2300 & 121.1300 & 83.48122 & $30.42602^{*}$ \\
BIST100 Index & $86,032.40$ & $83,268.04$ & $119,528.8$ & $55,099.33$ & $14,997.71$ & 3.480335 \\
Credit & $1,54 \mathrm{E}+09$ & $1,45 \mathrm{E}+09$ & $2,72 \mathrm{E}+09$ & $6,17 \mathrm{E}+09$ & $6,16 \mathrm{E}+08$ & $6.747303^{*}$ \\
Exchange (\$) & 3.343141 & 2.938345 & 6.344575 & 1.763170 & 1.434790 & $11.13840^{*}$ \\
Liquid & $1.41 \mathrm{E}+09$ & $1.28 \mathrm{E}+09$ & $2.78 \mathrm{E}+09$ & $6.97 \mathrm{E}+09$ & $5.49 \mathrm{E}+09$ & $8.828315^{*}$ \\
\hline
\end{tabular}

Source: Computed by the Author using Eviews 10. ${ }^{*}$ indicates no normal distribution.

In the descriptive statistics table, the mean, median, standard deviation, and Jargue-Bera are provided. The result of descriptive statistics indicated that the average CDS premium is 246.66 with standard deviation 83.48 , whereas the minimum value of CDS is 121.13 , and the maximum is 546.23 . The average of BIST100 index is $86,032.40$, the average domestic credit volume for the banking sector is $1,5 \mathrm{E}+09$, the average foreign exchange rate for USD is 3,34 , and the average of liquid liabilities is $1.41 \mathrm{E}+09$. According to the maximum and minimum, it is seen that all the data is in the positive range. In addition, the Jarque-Bera statistics suggest that the variables do not follow a normal distribution - except for the BIST100 index.

In the sequence, Figure 1 presents the plot graphs of the variables in the sample.

Figure 1 indicates the plots of variables over time in movements. The progress of the variables, which monotonically display a mixture of upward and downward sloping trends in terms of the existence of possible structural regimes, can be observed. It is observed in the graphics that none of the variables are in a distribution around a specific mean, therefore none of them are stationary. In general, these graphs indicate that in some periods, the variables 
appear to have strong relationships. The upward and downward trends in 2018 facts give us an idea of the close relationship between the CDS premium and financial variables in Turkey. As can be seen in Figure 1, and when the distribution of the CDS levels of Turkey from the second half of 2017 up to the present are analyzed, it can be observed that it is above level 500 for short intervals and also that it is not normal, it is right-skewed instead. It is observed that the CDS premium of Turkey has been in a continuous increase for the last 3 years despite the political uncertainties and the fluctuations during the year. The highest value of the monthly CDS premium is about 546 in the August 2018. CDS premium had returned to its pre-downturn rate at the end of 2018. CDS premium showed signs of a slight recovery at the end of 2018 and until the begining of 2019. The political tensions that occurred between the US and Turkey, presidential elections, and political uncertainty can be considered as reasons for the sudden rise of the CDS premium between 2017 and 2018.
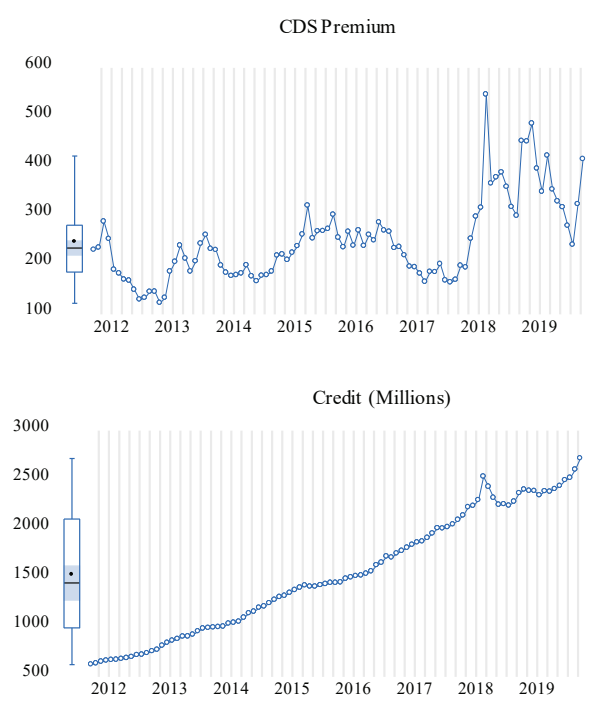
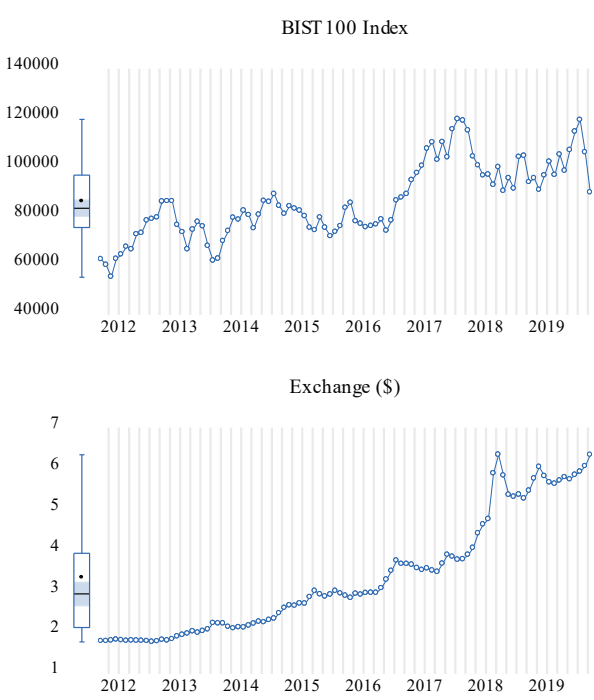

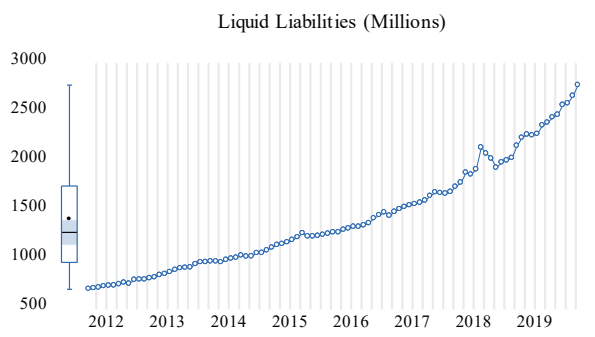

Figure 1. The Plot of the Data of Selected Financial Variables Source: Research data.

It is necessary to determine the stationarity levels of the series to decide on the tests which will examine the cointegration relationship between the variables. Therefore, the PP (1988) 
and Lee and Strazicich (2003) unit root tests are used in the study. The results of the PP (1988) unit root test and Lee and Strazicich (2003) with two structural breaks unit root test on the selected variables are presented in Table 2 and Table 3 , respectively.

Table 2

The Results of PP (1988) Unit Root Test

\begin{tabular}{lcccc}
\hline \multicolumn{2}{c}{ Variables } & \multicolumn{2}{c}{ Intercept Model } & \multicolumn{2}{c}{ Trend and Intercept Model } \\
\hline LDevel & 1st difference & Level & 1st difference \\
\hline BIST100 index & -1.950281 & $-10.20684^{*}$ & -3.145966 & $-10.21187^{*}$ \\
Credit & -2.209543 & $-9.139444^{*}$ & -2.913550 & $-9.151096^{*}$ \\
Exchange $(\$)$ & -1.820150 & $-7.680017^{*}$ & -1.583931 & $-7.764755^{*}$ \\
Liquid & 0.196739 & $-6.334209^{*}$ & -3.015902 & $-6.326625^{*}$ \\
\hline
\end{tabular}

Source: Computed by the Author using Eviews 10.

Notes: *, ** and ${ }^{* * *}$ denote the rejection of the null hypothesis at $1 \%, 5 \%$ and $10 \%$ level of significance respectively. MacKinnon (1996) critical values with constant are $-3.499(1 \%),-2.891(5 \%)$ and $-2.583(10 \%)$, MacKinnon (1996) critical values with constant and linear trend are $-4.056(1 \%),-3.457(5 \%)$ and $-3.154(10 \%)$. It was also determined that the series contain unit root in the level, and they are stationary for the first differences.

In the Table 2, it can be observed that the PP (1988) unit root test fails to reject the null hypothesis of a unit root at $1 \%$ and $5 \%$ significance levels in all variables in both the intercept model and the intercept and trend model. All of the variables have a unit root, in other words variables are not stationary at their level. However, they all become stationary at their first differences. The results of the unit root test implies that examination of possible cointegration relationship among the variables should occur.

The results of the two structural breaks unit root test of Lee-Strazicich (2003) can be observed in Table 3. The results revealed that the selected financial factors of Turkey are higher than the critical table values in the study of Lee-Strazicich (2003) for the A and C models, therefore they are non-stationarity at the significance levels of $\% 1$ and $\% 5$. It was observed that all series became stationary after their first difference. Thus, it was concluded that all variables have a unit root. During the period, it is observed that significant regime shifts occurred in the specified dates. The estimated breakpoints have been identified as 2015 and 2018 for the CDS premium, 2016 and 2017 for BIST100 index, 2015 and 2018 for the credit, 2017 and 2018 for the exchange, and 2015 and 2018 for the liquid liabilities. Within this frame, it is possible to say that the breaks on the CDS premium and other financial variables are considered as an important indicator related to the events in the economy. In other words, the estimated break dates suggest that important incidents are occuring in the Turkish economy.

According to the results of both unit root tests, all the variables are stationary at their first difference, the necessary condition for the test for cointegration has been fulfilled. After examining the stationarity test of the series and breaking dates, the next step involves applying the GH (1996) and Hatemi-J (2008) tests cointegration test to check whether there is a longterm cointegration relationship with structural breaks between the variables in the model. The 
GH (1996) test statistics are applied through two different models, and in the Hatemi-J (2008) two breaks test they are applied through a single model. Table 4 reports the results of this test for examining the long-run relationship between CDS premium and financial variables.

Table 3

The Results of Unit Root Test with Two Structural Breaks

\begin{tabular}{lcccc}
\hline \multirow{2}{*}{ Variables } & \multicolumn{3}{c}{ Lee and Strazicich (2003) LM Test } \\
\cline { 2 - 5 } & Model A & Breakpoints (TB $\left.\mathbf{T B}_{\mathbf{1}} \mathbf{T B}_{\mathbf{2}}\right)$ & Model C & Breakpoints $\left.\mathbf{( T B}_{\mathbf{1}}-\mathbf{T B}_{\mathbf{2}}\right)$ \\
\hline CDS premium & -3.566 & 2015:M02-2018:M08 & -3.855 & 2015:M09-2018:M08 \\
BIST100 Index & -3.746 & 2016:M12-2017:M06 & -4.489 & 2015:M09-2017:M05 \\
Credit & -2.156 & 2018:M08-2018:M10 & -5.081 & 2015:M09-2018:M07 \\
Exchange (\$) & -3.826 & 2017:M10-2018:M05 & -5.163 & 2018:M06-2018:M12 \\
Liquid & -2.959 & 2014:M09-2015:M09 & -5.191 & 2018:M01-2018:M09
\end{tabular}

Critical values for the LM unit root test statistic based on Model C

\begin{tabular}{lccccccccc}
$\lambda 2$ & 0.4 & & \multicolumn{9}{c}{0.6} & \multicolumn{3}{c}{0.8} \\
$\lambda 1$ & $\% 1$ & $\% 5$ & $\% 10$ & $\% 1$ & $\% 5$ & $\% 10$ & $\% 1$ & $\% 5$ & $\% 10$ \\
0.2 & -6.16 & -5.59 & -5.27 & -6.41 & -5.74 & -5.32 & -6.33 & -5.71 & -5.33 \\
0.4 & - & - & - & -6.45 & -5.67 & -5.31 & -6.42 & -5.65 & -5.32 \\
0.6 & - & - & - & - & - & - & -6.32 & -5.73 & -5.32 \\
\hline
\end{tabular}

Source: Computed by the Author using Gauss 21.

Notes: Lee and Strazicich (2003) indicate the LM-type two break unit root test. TB1 and TB2 are the break dates. The Model A and C denote the breaks on the intercept and the breaks on the intercept and trend, respectively. Critical values for the LM test based on Model A at $10 \%, 5 \%$ and $1 \%$ significant levels are $-3.504,-3.842$ and -4.545 respectively. Critical values for the other coefficients follow the standard normal distribution. $\lambda j$ denotes the location of breaks.

Table 4

The Results of GH (1996) and Hatemi- J (2008) Cointegration Tests

\begin{tabular}{lccccccc}
\hline Test & Model & ADF* & TB & Zt* $^{*}$ & TB & Za & TB \\
\hline GH & C & $-7.161^{*}$ & $2016: M 07$ & $-7.725^{*}$ & $2018: M 06$ & $-74.04^{* *}$ & $2018: M 06$ \\
GH & C/S & $-7.703^{*}$ & 2014:M04 & $-7.743^{*}$ & $2014: M 04$ & $-75.20^{* * *}$ & $2018: M 05$ \\
& & & $2013: M 12$ & $-9.121^{*}$ & $2014: M 01$ & -98.141 & $2014: M 01$ \\
HJ & C/S & $-8.702 *$ & 2017:M03 & & $2015: M 07$ & & $2015: M 05$ \\
\hline
\end{tabular}

Source: Computed by the Author using Eviews 10.

Notes: The GH test critical values are from Table 1 of GH (1996. p. 109), and HJ test critical values are from Table 1 of HJ (2008. p. 501). $T B$ denote the break points. $15 \%$ trimming region is used for the tests. The lag length was selected using Akaike Information Criterion out of a maximum lag of $12 .{ }^{*}$ and ${ }^{* *}$ denote the rejection of null hypothesis of no cointegration at the $1 \%$ and $5 \%$ significance levels, respectively. The $5 \%$ critical values for $\mathrm{ADF}$ (and $\mathrm{Z}_{\mathrm{t}}$ ) are $-5.56,-5.83$ and -6.41 , respectively while the $\mathrm{Z}_{\mathrm{a}}$ for the same equations are -59.40 , -65.44 and -78.52 , respectively. C, C/T and C/S denote level shifts, level shift with trend and regime shifts, respectively.

According to the results of the GH (1996) test; Model 1 (C), which allows for breaks in the intercept, and Model $3(\mathrm{C} / \mathrm{S})$ where regime change is tested $A D F^{*}, Z_{t}^{*}$ ve $Z_{\alpha}^{*}$ at a significance level of $10 \%$ or better; the absolute value of the test statistics was less than the table critical values for both models. Table 4 reports the results for the three models, indicating that when the CDS premium is the dependent variable the null hypothesis of no cointegration relationships is rejected and it is accepted that there is a long-term relationship between the series. According to the analysis results, it can be said that there is a long-term cointegration relationship between the CDS premium and the BIST100 index, credit, exchange, and liquid liabilities in both models. In other words, the cointegration relationship indicates that the relevant variables are effective on the CDS premium. When the results of the Hatemi-J (2008) 
structural break cointegration test are examined, the $A D F^{*}$ and $Z_{t}^{*}$ test statistics reject the null hypothesis at the $1 \%$ significance level. However, with the $Z_{\alpha}^{*}$ test statistic, the null hypothesis is accepted. Since the dimension feature of the $A D F^{*}$ test statistic is close to the nominal significance level, it can be observed that the dimension distortions are less. The $A D F^{*}$ test statistic and the $Z_{t}^{*}$ test statistic have the same asymptotic distribution (Mert and Caglar, 2019: 380). Therefore, it is observed that the results of the $A D F^{*}$ and $Z_{t}^{*}$ test statistics are lower than the table critical values in the regime change $(\mathrm{C} / \mathrm{S})$ test. In this case, the null hypothesis indicating that there is no cointegration relationship between the variables is rejected and it is concluded that there was a long-term relationship between the series. This result is in parallel with the GH (1996) cointegration test result, which takes the single structural break into account. The break dates were found because of both cointegration tests in which the relationship between the CDS premium and financial factors are determined as close dates. For the found break dates, 2014 and 2018 are both significant and remarkable. When the break dates corresponding to those years are analyzed, it is possible to say that they are related to the 17/25 December coup attempt and the following events, and the elections in 2018. It is possible to say that they are in parallel with the current condition of the Turkish economy since those break dates come after those events. As a result, the 17/25 December coup attempt, the political uncertainties after the 7 June elections, political tension between the US and Turkey, and the economic developments afterward caused the Turkish Lira to significantly lose its value and affected the CDS premium negatively. Consequently, the recent economic and political events in Turkey have caused the CDS premium to increase swiftly. Given the cointegration relations between the CDS premium and financial drivers, the findings comply with the studies of Gun et al. (2016). After the cointegration relationship between the variables is found, the long-term analysis is started by the FMOLS estimator.

In the long-term, the model estimated to observe how financial drivers affect Turkey's CDS premium is provided below.

$$
C D S_{t}=b_{0}+b_{1} B I S T_{t}+b_{2} \operatorname{CREDIT}_{t}+b_{3} E X C_{t}+b_{4} L I Q_{t}+e_{t}
$$

Here, $C D S$ indicates credit default swaps, BIST indicates BIST-100 index, CREDIT indicates domestic credit volume in the banking sector, EXC indicates dollar exchange rate, and $L I Q$ indicates the liquid liabilities. Finally, $b 0$ and $e t$ is the constant and error term, respectively.

At this stage. 01/2014 and 07/2015, which are the dates of breaks for the $Z_{t}^{*}$ statistic are included in the model as $d 1$ and $d 2$ dummy variables by taking the regime change $(\mathrm{C} / \mathrm{S})$ which is based on the Hatemi-J (2008) cointegration test into consideration. In the study, the long-term cointegration coefficients and the model in which the dummy variables provided in equation (18) as independent variables are estimated through FMOLS. The variables which have cointegration relationships between each other and the results of the FMOLS model which is formulated with the break dates are presented in Table 5 . 
Table 5

The Results of FMOLS Estimator

\begin{tabular}{|c|c|c|c|c|}
\hline $\begin{array}{l}\text { Dependent } \\
\text { Variable }\end{array}$ & Coefficient & Std. Error & t-Statistic & Prob. \\
\hline BIST100 index & -1.630801 & 0.382762 & -4.260612 & $0.0001^{*}$ \\
\hline Credit & 3.847111 & 1.436125 & 2.678813 & $0.0089^{*}$ \\
\hline Exchange rate $(\$)$ & 1.130966 & 1.520638 & 0.743745 & 0.4592 \\
\hline Liquid liabilities & -5.200600 & 2.060450 & -2.524012 & $0.0136^{* *}$ \\
\hline $\mathrm{C}$ & 50.73411 & 17.56854 & 2.887782 & $0.0050^{*}$ \\
\hline $\mathrm{d}_{1}$ & 23.96213 & 39.54010 & 0.606021 & $0.0546^{* * *}$ \\
\hline $\mathrm{d}_{2}$ & 5.251749 & 35.87711 & 0.146382 & 0.8840 \\
\hline
\end{tabular}

Source: Computed by the Author using Eviews 10.

Notes: ${ }^{*}{ }^{* *}$ and ${ }^{* * *}$ indicate $1 \%, 5 \%$ and $10 \%$ level of significance, respectively. Intercepts and linear trends are included in the regressions. Barlett Kernel with a fixed bandwidth of 4 was used following. The model has good explanatory power: $\mathrm{R}^{2}$ is calculated as 0.9342 , meaning that approximately $93.42 \%$ of the total sample variation of the CDS premium is explained by the independent variables.

When the coefficients in Table 5 are analysed, it can be observed that the coefficients of the variables, except for the $\mathrm{d}_{2}$ dummy variable which is included in the model as the representative of the $07 / 2015$ break period and the foreign exchange variable, are found as statistically significant at the $1 \%$ and $5 \%$ significance levels.

According to the results obtained from the FMOLS model, it can be concluded that in a long-term period, changes in the BIST100 index and liquid liabilities affect the CDS premium significantly and negatively. On the other hand, changes in the banking sector credit volume affect the CDS premium significantly and positively. According to the results of the FMOLS, there is an opposite relationship between the CDS premium, BIST100 index and liquid liabilities. No type of relationship of CDS premium with the foreign exchange rate and $\mathrm{d} 2 \mathrm{dummy}$ variables is found. The BIST100 index and liquid liabilities affect the CDS premium negatively and statistically significantly as expected with theoretical expectations. Accordingly, a $1 \%$ increase in the BIST100 index causes a $1.63 \%$ decrease in the CDS premium in the long-term period. Another result is that there is a negative relationship at the $5 \%$ significance level, determined between the CDS premium and liquid liabilities. According to this result, a $1 \%$ increase in liquid liabilities causes a $5.20 \%$ decrease in the CDS premium in the longterm premium. Another result is that the banking sector domestic credit volume affects the CDS premium positively and statistically significantly, in line with theoretical expectations. According to the result, a 1\% increase in the banking sector's domestic credit volume causes an increase of $3.84 \%$ on the CDS premium in the long-term period. Additionally, while a $1 \%$ increase in the exchange rate reduces the CDS premium by $1.13 \%$, the coefficient is insignificant.

The FMOLS estimator also reveals the effects of the shocks within the structural break dates on the long-term relationships between the series. When the dummy variables representing the periods 01/2014 and 07/2015 are analysed, while the $\mathrm{d}_{1}$ dummy variable representing the period $01 / 2014$ is statistically significant, the $d_{2}$ dummy variable is statistically 
insignificant. The effect of the economic and political events in the period 01/2014 (which is one of the structural break dates on the long-term relationship between the series) is statistically significant and positive. With this result, the significance of the $d_{1}$ dummy variable used in the cointegration coefficient estimations is important in terms of verifying that the determining date is the year when important changes occurred in the Turkish economy. On the other hand, the coefficient values related to the FMOLS estimator indicate that liquid liabilities are the most important variable affecting the CDS premium in Turkey among the macro-financial factors analysed in the study. As a result, the increasing level of liquid liabilities, and BIST100 index in a long-term period in Turkey will decrease the CDS premium and the increasing level of banking sector domestic credit volume will increase the level of CDS premium. In the study, in which the relationship between the BIST100 index, liquid liabilities and banking domestic credit volume is determined, the explanation power of the model formed through the results of the FMOLS analysis is found as $92 \%$. Those findings are consistent with the theoretical expectations. The opposite relationship between the BIST100 index and CDS premium can be explained as follows: when the fact that the stock market gains value which we used for explaining the sovereign risk premium is considered, it is possible to say that the entrances caused by the progress on the domestic and foreign risk desire have a decreasing effect on the risk premiums. This is because the stocks gaining value can cause lower borrowing costs for the investors. Moreover, the stock markets are the markets in which the marketable securities can be turned into cash. Thanks to this characteristic of the stock markets, the hesitation of the investor for investing in the stock markets decreases. This is because, the high number of sellers and buyers within the stock markets enables the progress of the stock markets swiftly and with high cash flow. Also, it is observed that the investors of the Istanbul Stock Exchange have determined their positions depending on the CDS values recently. In periods when the risk perception is lower, i.e. when the CDS premium is lower, it is observed that the value of the Istanbul Stock Exchange gets higher. It is possible to say that a great share of the foreign investors in the stock markets has a role in this parallelism between the stock market and the risk perception. As a result, the stock markets contribute to decreasing the sovereign risk premium of the relevant country with their role in enabling the protection, purchasing and sale transactions to be carried out within a frame of specific rules. The opposite relationship between the liquid liabilities and the CDS premium can be explained as follows: the money supply is the total amount of money that can be used by the economic units within an economy to perform their short-term obligations. Within this frame, it is observed that in case the money supply decreases in an economy, the interest rates increase and the prices and the production decreases. This causes insufficient use of the production capacity and a decrease in investments. Similarly, the investments increase when the interest rates decrease because of the increase in the money supply, and the increase in the investments increases the product. Therefore, absence of the liquidity in the markets has an important role in the decrease in the CDS premium. Finally, the positive relationship 
between the banking sector domestic credit volume and CDS premium can be explained as follows: the banks cannot collect the cash receivables caused by the credits and marketable securities, either completely or partially. Eventually, the non-performing loans arise. When it is considered with the perception of the borrowing company, the new funding and investment opportunities become limited since the transformation of the borrowed credit to the non-performing loan bind the deposit. The investment desire and credit demand of a company whose debts are accumulated decrease. This can cause a great block in the country's economy and increase the sovereign risk premium. As a matter of fact, in several studies, it was concluded that there is a significant relationship between non-performing loans and banking sector total credit volume and this relationship is positive (Vazquez et al., 2012; Messai and Jouini, 2013; Ahmad and Bashir, 2013; Vithessonthi, 2016; Kara and Bas, 2019). In other words, an increase in non-performing loans is observed in parallel with the increasing credit volume. The increase in non-performing loans will cause a decrease in their performance by decreasing their profitability. The performance of the banking sector has an important role in the change of the CDS premium. Therefore, it is not surprising that a shock to the banking system of a country has important effects on the sovereign default risk. An increase in the performance of the banking sector causes a decrease in the CDS premium, the decrease will cause the CDS premium to increase. This result is consistent with the result of Telek and Sit (2017).

When all of the results obtained from the FMOLS are evaluated, it is concluded that liquid liabilities have the greatest effect among the selected factors, the banking sector domestic credit volume and BIST-100 have less effect on the CDS premium when they are compared with the liquid liabilities. The results are consistent with theoretical assumptions in most of the cases. The coefficients found related to the variables and direction of the relationships are in parallel with the studies conducted by Pan and Singleton (2008), Longstaff et al. (2011), Liu and Morley (2012), Ertugrul and Ozturk (2013), Hanci (2014), Eren and Basar (2016), Basarir and Keten (2016), Yenice and Hazar (2015), Akkaya (2017), Munyas (2018) and Sadeghzadeh (2019).

\section{Conclusion and Policy Recommendations}

Political and economic uncertainties in a country and tensions in foreign relations can be effective in the increase of the CDS premium. With the deterioration of economic and financial indicators experienced in a country and the existence of political instability, an increase in CDS premium will be observed. The higher the CDS premium is paid for a country's borrowing tool indicates the higher the risks for that country. Countries with high CDS premiums must bear higher costs. Similarly, countries with low CDS premiums borrow at lower costs. At the same time, the higher the CDS score, the more likely that country will not pay its debts. Therefore, the CDS are of great importance for both investors and countries in need 
of capital. Countries with low CDS premiums can obtain funds from international markets both more easily and at a lower cost. Investors, on the other hand, can direct their investments more safely and suitably by comparing country CDS premium between countries. Accordingly, finding appropriate determinants and understanding their effect on CDS premiums is crucial and beneficial for investors, analysts, or policymakers.

This study has two aims. The first aim of the study is to determine the structural breaks in the CDS premium calculated for Turkey and the economic and political reasons underlying those breaks. The second aim of the study is to analyze the effect of financial factors on the CDS premium and to reveal the relationship between financial stability and the CDS premium.

When the FMOLS test results are analyzed, it can be observed that there is a statistically significant relationship between the CDS premium and the BIST100 index, liquid liabilities, and banking domestic credit volume. There is a negative relationship between the CDS premium and BIST100 index and liquid liabilities, and there is a positive relationship with the banking domestic loan volume. In other words, an increase in the BIST100 index and liquid liabilities decreases the CDS premium, while an increase in the banking domestic loan volume increases the CDS premium. However, it is observed that the most important factor among the financial factors analysed in this study affecting the CDS premium of Turkey is the liquid liabilities in terms of the coefficient values related to the FMOLS. The FMOLS also reveals the effect of shocks at the dates of the structural break on the long-term relationship between series. The effect of the 17/25 December coup attempt in 01/2014, which is one of the structural break dates, on the long-term relationship between the series is statistically significant and positive. The break dates determined by the cointegration method indicate that there has been a significant change in the economy.

The CDS premium reflects the economic and financial performance of a country and directly affects the costs of using external financing. If the CDS premium increases, the country's economies will have to borrow with much more interest both abroad and domestically. It is known that with the increase in risk premiums, international investors tend to exit their markets. Consequently, liquidity problems increase in the markets. Additionally, international investors may cause a decrease in their risk desire for the financial assets of the countries with high CDS premiums. For this reason, it should be concluded that economies with a desire to reduce the CDS premium or sovereign risk should intensify efforts to ensure financial stability. Accordingly, it is necessary to carry out empirical studies related to the usage of the micro and macro drivers the minimize the CDS premium in emerging countries. For future research, investigating the effects of different variables with different econometric methods such as the Maki (2012) test might also be considered. However, the proliferation of the COVID-19 pandemic process, which started in January 2020 in many countries, caused changes in the fields of political, social, economic, and cultural. Countries have put into effect imperative new 
applications in many fields. Hence, it is recommended to consider the effects of the economic conjuncture and global crises such as pandemic for the studies to be conducted and investigate their impact on the business world in the future. The findings of this study are expected to offer insight into the financial policymakers and for future studies.

\section{References}

Adom, P. K., Amakye, K., Barnor C., \& Quartey, G. (2015). The long-run impact of idiosyncratic and common shocks on industry output in Ghana. OPEC Energy Review, 39(1), 17-52.

Ahmad, F., \& Bashir, T. (2013). Explanatory power of bank specific variables as determinants of non-performing loans: Evidence from Pakistan banking sector. World Applied Sciences Journal, 22(9), 1220-1231.

Aizenman, J., Hutchison, M. M., \& Jinjarak, Y. (2013). What is the risk of European sovereign debt defaults? Fiscal space, CDS spreads and market pricing of risk. Journal of International Money and Finance, Elsevier, 34(C), 37-59.

Akkaya, M. (2017). Analysis of internal factors affecting CDS premium of Turkish treasuries. Journal of Finance Letters, 107, 129-146.

Aksoylu, E., \& Gormus, S. (2018). Credit default swaps as an indicator of sovereign risk in developing countries: Asymmetric causality method. The International Journal of Economic and Social Research, 14(1), 15-33.

Altay, H., \& Yilmaz, A. (2016). Analysing the effect of export on employment in Turkish economy. Finans Politik \& Ekonomik Yorumlar, 53(616), 75-86.

Amato, J. (2005). Risk aversion and risk premia in the CDS market. BIS Quarterly Review, December, 55-68.

Atmisdortoglu, A. (2019). Credit default swaps and the research on selected indicators in emerging markets. PressAcademia Procedia, 10, 42-49.

Avci, O. B. (2020). Interaction between CDS premium and stock markets: Case of Turkey. Academic Review of Economics and Administrative Sciences, 13(1), 1-8.

Baltaci, N., Akyol, H. (2016). Examination of the macroeconomic variables affecting credit default swaps. Journal of Eco. Bibliography, 3(4), 610-625.

Basarir, C., \& Keten, M. (2016). A cointegration analysis between CDS premium, stock indexes and exchange rates in emerging countries. Mehmet Akif Ersoy University Jou. of Soc. Sciences Institute, 8(15), 369-380.

Bashier, A. A., \& Siam, A. J. (2014). Immigration and economic growth in Jordan: FMOLS approach. International Journal of Humanities Social Sciences and Education, 1(9), 85-92.

Bozkurt, C., \& Okumus, I. (2015). The effects of economic growth, energy consumption, trade openness and population density on co2 emissions in Turkey: A cointegration analysis with structural breaks. Mustafa Kemal University Journal of Social Sciences Institute, 12(32), 23-35. 
Bozkurt, I. (2015). Determination of the relationship between financial stability and CDS premium by using fuzzy regression analysis: Evidence from Turkey. Gümüşhane Univ. Jou. of Soc. Sciences Institute, 6(13), 64-80.

Caglar, A. E., \& Mert, M. (2017). Environmental Kuznets hypothesis and the 1mpact of renewable energy consumption on carbon emissions in Turkey: Cointegration with structural breaks approach. Journal of Management and Economics, 24(1), 21-38.

Chan, K. C., Fung, H. G., \& Zhang, G. (2008). On the relationship between Asian sovereign credit default swap markets and equity markets. Journal of Asia Business Studies, 4(1), 1-31.

Coronado, M., Corzo, M. T., \& Lazcano, L. (2012). A case for Europe: The relationship between sovereign CDS and stock indexes. Frontiers in Finance and Economics, 9(2), 32-63.

Danaci, M. C., Sit, M., Sit, A. (2017). Relationship between credit default swaps (CDS) and growth rate: A case of Turkey. Journal of Aksaray University Faculty of Econ. and Admin. Sciences, 9(2), 67-78.

Degirmenci, N., \& Pabuccu, H. (2016). Relationship between Istanbul stock market and credit default swap: VAR and NARX model. The Journal of Academic Social Science, 4(35), 248-261.

Dinc, M., Yildiz, U., \& Kirca, M. (2018). Econometric analysis of structural breaks in Turkey's credit default swap (CDS). International Journal of Econ. and Admin. Studies, 2018(Special Issue), 181-182.

Eren, M., \& Basar, S. (2016). Effects of credit default swaps (CDS) on BIST-100 index. Ecoforum, 5(Special Issue), 123-129.

Ersan, I., \& Gunay, S. (2009). Kredi riski göstergesi olarak kredi temerrüt swapları (CDSs) ve kapatma davasinin Türkiye riski üzerine etkisine dair bir uygulama. Bankacılar Dergisi, 71, 3-22.

Ertugrul, H. M., \& Ozturk, H. (2013). The drivers of credit default swap prices: Evidence from selected emerging market countries. Emerging Markets Finance \& Trade, 49(5), 228-249.

Eyssell, T., Fung, H. G., \& Zhang, G. (2013). Determinants and price discovery of china sovereign credit default swaps. China Economic Review, 24, 1-15.

Fender, I., Hayo, B., \& Neuenkirch, M. (2012). Daily pricing of emerging market sovereign CDS before and during the global financial crisis. Journal of Banking and Finance, 36(10), 2786-2794.

Fontana, A., \& Scheicher, M. (2010). An analysis of euro area sovereign CDS. European Central Bank Working Paper Series, No.1271.

Fontana, A., \& Scheicher, M. (2016). An analysis of euro area sovereign CDS and Their relation with government bonds. Journal of Banking \& Finance, Elsevier, 62(C), 126-140.

Gregory, A. W., \& Hansen, B. E. (1996). Residual-based tests for cointegration in models with regime shifts. Journal of Econometrics, 70, 99-126.

Gun, M., Kutlu, M., \& Karamustafa, O. (2016). The effects of Gezi Park protests on Turkey's credit default swaps (CDS). Journal of Business Research-Turk, 8(1), 556-575.

Hanci, G. (2014). Analyzing the relationship between the credit default swaps and BIST-100. Journal of Finance Letters, 28(102), 9-22.

Hatemi-J, A. (2008). Tests for cointegration with two unknown regime shifts with an application to financial market integration. Empirical Economics, 35, 497-505.

https://tr.investing.com/rates-bonds/turkey-cds-5-year-usd

https://www.tcmb.gov.tr/wps/wcm/connect/EN/TCMB+EN/Main+Menu/Statistics

Hull, J., \& White, A. (2001). Valuing credit default swaps II: Modelling default correlations. Journal of Derivatives, 8(3), 12-22. 
Hull, J. C. (2012). Options, Futures and Other Derivatives. Pearson Education Ltd., United Kingdom.

Hull, J., Predescu, M., \& White, A. (2004). The relationship between credit default swap spreads, bond yields, and credit rating announcements. Journal of Banking \& Finance, 28(11), 2789-2811.

Kara, M., \& Bas, G. (2019). The effect of growth in total credit size on non-performing loans. Journal of Social, Humanities and Administrative Sciences, 5(16), 351-357.

Kilci, E. N. (2019). Analysis of the impact of foreign debt on sovereign CDS premium: The case of Turkey. Journal of Turkish Court of Accounts, 112, 75-92.

Kocsis, Z., \& Monostori, Z. (2016). The role of country-specific fundamentals in sovereign CDS spreads: Eastern European experiences. Emerging Markets Review, 27, 140-168.

Koy, A. (2014). An empirical study on credit default swaps' spreads and bond spreads. International Review of Economics and Management, 2(2), 63-79.

Le, T. H., \& Chang, Y. (2012). Oil price shocks and gold returns. International Economics, 131, 71-104.

Lee, J., \& Strazicich, M. C. (2003). Minimum LM unit root test with two structural breaks. The Review of Economics and Statistics, 85(4), 1082-1089.

Liu, Y., \& Morley, B. (2012). Sovereign credit default swaps and the macroeconomy. Applied Economics Letters 19, 129-132.

Longstaff, F. A, Pan, J., Pedersen, L. H., \& Singleton, K. J. (2011). How sovereign is sovereign credit risk? American Economic Journal: Macroeconomics, 3(2), 75-103.

Maki, D. (2012). Tests for cointegration allowing for an unknown number of breaks. Economic Modelling, 29(5), 2011-2015.

Mateev, M., \& Marinova, E. (2019). Relation between credit default swap spreads and stock prices: A non-linear perspective. Journal of Economics and Finance, 43, 1-26.

Mehmood, B., \& Shahid, A. (2014). Aviation demand and economic growth in the Czech Republic: Cointegration estimation and causality analysis. Statistika, 94(1), 54-63.

Mert, M., \& Caglar, A. E. (2019). Eviews and Gauss Uygulamalı Zaman Serileri Analizi. Detay Publication, Ankara.

Messai, A. S., \& Jouini, F. (2013). Micro and macro determinants of non-performing loans. International Journal of Economics and Financial Issues, 3(4), 852-860.

Munyas, T. (2018). An econometric analysis related to evaluating to the relation between CDS premium and market data: A case study in Turkey. Atlas Int. Ref. Jou. on Social Sciences, 4(15), 1689-1696.

Pan, J., \& Singleton, K. J. (2008). Default and recovery implicit in the term structure of sovereign CDS spreads. The Journal of Finance, 63(5), 2345-2384.

Phillips, P. C. B., \& Hansen, B. E. (1990). Statistical inference in instrumental variables regression with I(1) processes. Review of Eco. Studies, 57, 99-125.

Phillips, P. C. B., \& Perron, P. (1988). Testing for a unit root in time series regression. Biometrica, 75(2), 335-346.

Sadeghzadeh, K. (2019). Sensitivity of stock indices to country risks: Analysis on selected countries. Atatürk University Journal of Economics and Administrative Sciences, 33(2) 435-450.

Sarigul, H., \& Sengelen, H. E. (2020). The link between sovereign credit default swaps and bank stock prices: An empirical study on bank stocks in the Borsa Istanbul. The Journal of Accounting and Finance, 86, 205-222. 
Sevil, G., \& Unkaracalar, T. (2020). An assessment of the relationship between CDS spreads and portfolio investments: Turkey case. Journal of Finance Letters, 113, 285-300.

Stock, J. H., \& Watson, M. (1993). A simple estimator of cointegrating vectors in higher order integrated systems. Econometrica, 61, 783-820.

Telek, C., \& Sit, A. (2017). The examination of the relationship between non-performing loans and risk premiums in Turkey: the term of 2005-2015. Int. Jou. of Disciplines Econ. \& Administ. Sci. Studies, 3(3), 152-161.

Vazquez, F., Tabak, B., \& Souto, M. (2012). A macro stress test model of credit risk for the Brazilian banking sector. Journal of Financial Stability, 8(2), 69-83.

Vithessonthi, C. (2016). Deflation, bank credit growth, and non-performing loans: Evidence from Japan. International Review of Financial Analysis, 45, 295-305.

Yenice, S., \& Hazar, A. (2015). A study for the interaction between risk premiums and stock exchange in developing countries. Journal of Economics, Finance and Accounting, 2(2), 135-151.

Yilanci, V., \& Ozcan, B. (2010). Analyzing the relationship between defence expenditures and GNP for Turkey under structural breaks. Cumhuriyet Univ. Jou. of Econ. and Administ. Sciences, 11(1), 21-33.

Zhang, G., Yau, J., \& Fung, H. G. (2010). Do credit default swaps predict currency values? Applied Financial Economics, 20(6), 439-458.

Zivot, E., \& Andrews, D. W. K. (1992). Further evidence on the great crash, the oil price shock and the unit root hypothesis. Journal of Business and Economic Statistics, 10(3), 251-270. 